\title{
Time Lag between Economic Development and Flood Fatality
}

\author{
Guangwei Huang ${ }^{1}$ \\ ${ }^{1}$ Graduate School of Global Environmental Studies, Sophia University, Tokyo, Japan \\ Correspondence: Guangwei Huang, Graduate School of Global Environmental Studies, Sophia University, 7-1, \\ Kioicho, Chiyodaku, Tokyo, 102-8554, Japan. Tel: 81-3-3238-4667. E-mail: huang@genv.sophia.ac.jp
}

Received: August 23, 2012 Accepted: September 20, 2012 Online Published: September 25, 2012

doi:10.5539/jsd.v5n10p50

URL: http://dx.doi.org/10.5539/jsd.v5n10p50

\begin{abstract}
Economic development allows a country to better manage and mitigate the risk from disasters. This paper presents a case study aimed at clarifying the relationship between economic development and flood fatality change. The focus is the largest city of China-Chongqing City that is located in Southwest China. The economy of the city jump-started in 1998 since it was raised to be one of the four municipalities under direct control of China's central government. By analyzing various data for the 10-year period after its takeoff, it was found that although economic development allows a region to better manage and mitigate the risk from disasters in theory, the flood fatality reduction may not be realized immediately. There was at least a 10 -year time lag between economic growth and flood fatality reduction in Chongqing. The high investment in water-related infrastructures along large rivers owing to economic growth was offset by irrational urban development along tributaries.
\end{abstract}

Keywords: flood fatality, GDP, annual total runoff of surface waters, Chongqing City

\section{Introduction}

Flooding is a serious, common, and costly hazard that many countries face regularly. Dilley, Chen and Deichmann (2005) estimated that more than one-third of the world's land area is flood-prone affecting some 82 percent of the world's population. Between 1975 and 2000, over 170 thousand people were killed by floods, making floods one of the most severe types of the natural disasters. In response to this threat, research works have been conducted to estimate flood-caused life-loss for the purpose of disaster reduction. Consequences of natural hazard events can be grouped into two general categories; economic losses and casualties (fatalities and injuries). Contemporary hazard research focuses more on economic losses and loss reduction rather than examining casualties (Borden \& Cutter, 2008). Kellenberg and Mobarak (2008) reported their finding that for certain types of disasters, death tolls increase with rising income before they decrease. Since human cost is the most severe consequence of flooding, and its response to economic development is less studied and controversial, the present work focused on flood fatality change.

Boyd (2005) derived a S-shaped relationship between flood mortality and depth. Duiser (1989) also proposed a model that relates the local mortality fraction to the flood depth. Jonkman (2008) proposed a framework that takes into account the flood characteristics, evacuation, availability of shelter and rescue as well. The 'Life Safety Model' developed by British Columbia Hydro (Watson et al., 2001; Johnstone et al., 2005) takes into account the hydraulic characteristics of the flood, the presence of people in the inundated area and the effectiveness of evacuation. An individual's fate is modeled mechanistically, i.e. individual behavior causes of death are accounted for at an individual level. In U.S, a model abbreviated as LIFESim has been developed to provide estimates of life loss due to dam failure (Aboelata \& Bowles, 2006), which used life-loss probability distributions developed by McClelland and Bowles (2000). On the other hand, Jonkman (2005) showed that males are highly vulnerable to dying in floods and unnecessary risk-taking behavior contributes significantly to flood disaster deaths. These studies have greatly improved the understanding on flood-caused life-loss mechanisms and are useful in making plan for flood disaster reduction. However, a common limitation of the existing approaches is that they could not explain the long-term change of flood fatality or mortality with changing socio-economic conditions. For instance, the great uncertainty associated with parameters of LIFEsim model rendered it inapplicable to the study of mortality change over time. In the model employed by Peduzzi, Dao, Herold and Mouton (2009), socio-economic variables were introduced into the model structure. However, a weighted average over time was indeed used in actual estimation so that it was not a dynamic model. Consequently, the model could not be used to study the temporal change of flood mortality with evolving 
economy. Overall, methods available for estimating flood-induced fatality or mortality at present are still limited in number and in its capability of explaining the relationship with changing social conditions such as economic development.

On the other hand, it is a common understanding that there is an intrinsic relationship between poverty and flood fatality. The logic is that poverty affects people's capacity to protect themselves and their ability to live in areas having less exposure to flood risk; and economic development allows a country to better manage and mitigate the risk from disasters. Empirical research works using cross-sectional or panel macro data (e.g. UNDP, 2004; Kahn, 2005; Toya \& Skidmore, 2007) report results that are broadly supportive of this logic. Adopting this view also lends itself to a simple and attractive macro-level policy prescription to manage the human and economic risk from natural disasters: allow countries to develop, and the risk of disaster damages should fall. Indeed, some policy analysts have argued that the best way to avoid large disaster damages is for poor countries to develop and grow faster (Okonski, 2004; Hoke, 2005).

The Intergovernmental Panel on Climate Change (2001) reports that $65 \%$ of world deaths from natural disasters between 1985 and 1999 took place in nations whose incomes were below $\$ 760$ per capita. In Bangladeshi, about 40 percent of the country was flooded in 1987, affecting 30 million people and caused about 1800 deaths. The floods in 1988 were even more serious, covering about 60 percent of the land area, affecting about 45 million people, and causing more than 2,300 deaths (Ninno et al., 2001). In the year 2004, devastating monsoon flood submerged two-thirds of the country, 35.9 million people affected, 726 deaths, millions of people made homeless (Rayhan \& Grote, 2007). In Pakistan, the 2010 flood has disproportionately affected its poorest regions, southern Punjab and rural Sindh where deprivation levels are high and the infrastructure is poor. The majority of the population in these regions is highly dependent on crop income with less diversification in their sources of income. 40 percent of the population lives below the poverty line, and 82 percent live on less than US $\$ 2$ per day. The flood has snatched their limited assets and livelihoods and has pushed them into extreme poverty (WFP, 2010). During the Venezuela floods of 1999 , as many as 30,000 people died and 150,000 to 200,000 people were made homeless and many of the victims were poor people according to the report by Commission of European Communities. Peduzzi et al. (2002) indicated that least developed countries account for $53 \%$ of flood casualties while the most developed countries account only for $1.8 \%$ of all victims. These above-mentioned facts gave strong support to the general perception that poorest societies are most vulnerable to flood disasters. However, the reverse question - "does the economic growth lead to significant reduction of flood death toll?" remains largely unexplored.

The present work is a case study exploring the long-term change of flood fatality in relation to economic boom. The main target of the present study is the Chongqing City, which is the largest city of China at present. Aiming at clarifying the relationship between economic growth and flood fatality in the city, data covering its economic boom period were analyzed in a holistic but unconventional manner leading to better understanding of the determinants of flood fatality. Besides, the relationship between economic growth and flood fatality at the national level was also discussed.

\section{Material and Method}

\subsection{Study Site Description}

Chongqing City is located on the upper reach of the Yangtze River in the mountainous areas in the southwest of China. It became one of the four direct-controlled municipalities in China in 1998, and the only such municipality in inland China (the other three are Beijing, Shanghai and Tianjin). The central urban area of Chongqing is situated at the confluence of Yangtze River and Jialing River. Figure 1 presents a geographical view of the location. It is $470 \mathrm{~km}$ from east to west and $470 \mathrm{~km}$ from north to south. The history of Chongqing extends back at least 3000 years. It has now jurisdiction over 40 districts and counties (autonomous counties and cities) and covers an area of $8.240 .000 \mathrm{~km}^{2}$ with a population of 31.590 .000 . Therefore, Chongqing is the largest city of China in terms of population and area. 


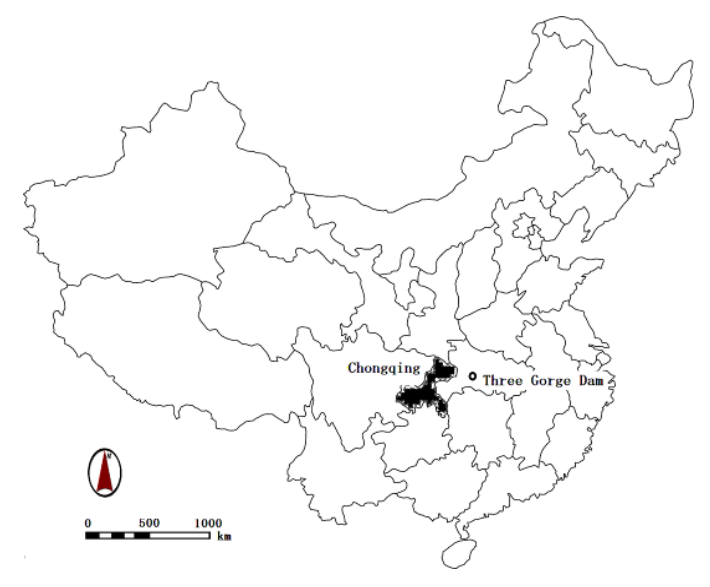

Figure 1. Location of Chongqing City within China

Figure 2 outlines the evolution of Chongqing's urbanization over the past three decades. In the 1970s, the urbanized area was mainly confined to the Yuzhong District, which is on a narrow peninsula formed between the Yangtze River and Jialing River. During the period of 1989-1997, the urban area expanded but not very significant. However, during the 10 -year period after being raised in its administrative status, the urbanization progressed very rapidly toward the North, the South and the West.

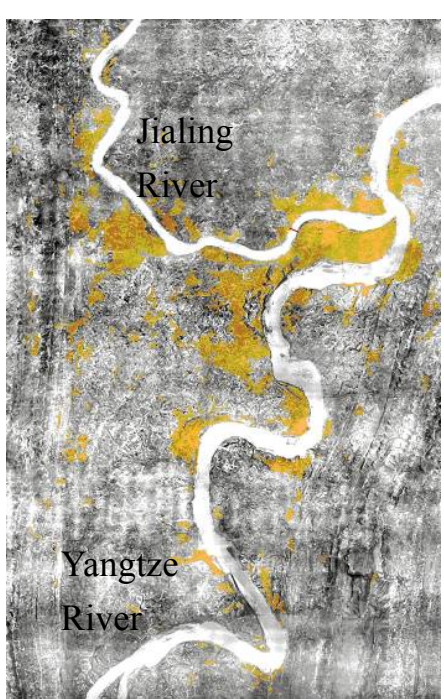

1979

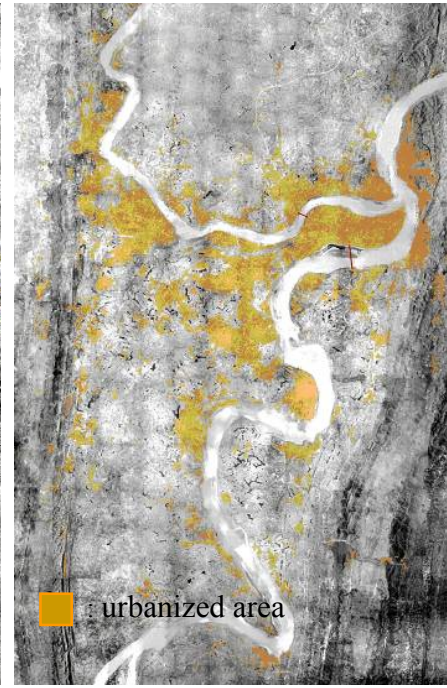

1987 


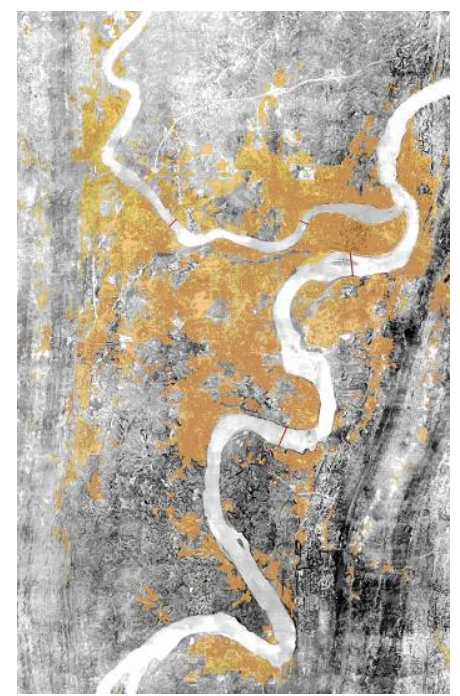

1997

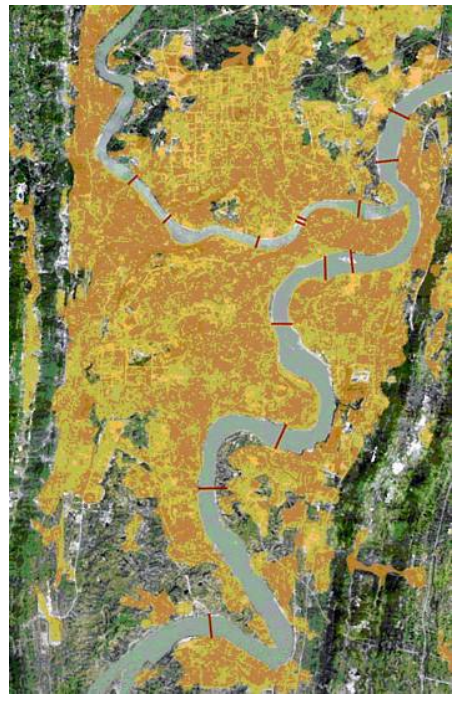

2008

Figure 2. Urbanization process in Chongqing (source: Chongqing Urban Planning Bureau)

Figure 3 shows that the total population of Chongqing had a V-shape change over 10 years aftern its economic take-off. There was virtually no difference in the total population between 1989 and 2010. However, the percentage of people living in urbanized areas in Chonqing increased from $30 \%$ to $55 \%$ over the period. At present, the density over all urbanized districts and counties is 1005 people per $\mathrm{km}^{2}$, which takes the $7^{\text {th }}$ position among Chinese cities.

Chongqing has a complex geological conformation. Mountains and hills account for $75 \%$ and $18 \%$ of its area, respectively. Flat area is less than $10 \%$ of its area. Due to the limited land availability, development of flood plains and subsequently exposure of dwellers to high flood risk become unavoidable with the increase of urban population. Chongqing is also characterized by abundant waterways. In addition to the Yangtze River and Jialing River, there are another 11 tributaries of the Yangtze River having a drainage area larger than $3000 \mathrm{~km}^{2}$ and 40 tributaries with a drainage area larger than $500 \mathrm{~km}^{2}$.

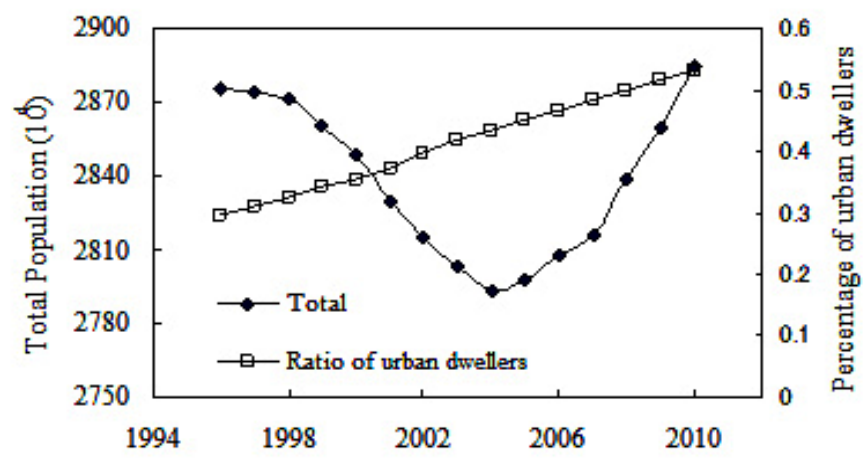

Figure 3. Changes of population and percentage of urban dwellers in Chongqing

\subsection{Methodology}

Various data of Chongqing City such as population, GDP, river runoff and flood disaster records were collected from Chongqing Municipality. Then, multi-regression analysis was conducted. However, the analysis was not conducted event-by-event. Instead, the focus was placed on the yearly variation of flood fatality during its economical boom. Previous studies (Peduzzi et al., 2009) attempted to link flood mortality with flood frequency that requires long-term data to determine the flood frequency of a given magnitude. In the present study, a different approach was taken that analyzed the death tolls on the basis of the annual total runoff of surface waters generated within the Chongqing City. The annual total runoff of surface waters in a region refers to the amount 
of runoff generated by rainfall in that region. Mathematically, it is expressed as

$$
R_{s}=R_{d-o}-R_{u-o}+\sum \text { loss } \pm \Delta S
$$

where $R_{s}=$ annual total runoff of surface waters generated naturally in a region; $R_{d-o}=$ observed total runoff of surface waters at the downstream control station of the region; $R_{u-0}=$ observed total runoff of surface waters at the upstream control station of the region; $\sum$ loss=various losses in the region including the water consumptions by industry and agriculture; $\Delta S=$ storage change including river base flow and exchange with groundwater. Losses and storage change are estimated according to China's standards of water resources survey and assessment or the guide to water resources assessment issued by the Ministry of Water Resources of China. They are referred to as re-establishment of natural runoff or restoring computation of runoff in Chinese water resources literature because the purpose of these calculations is to obtain the naturally generated surface runoff in a particular region $(\mathrm{Lu}, 2000)$ One can realize from Equation 1 that the annual total runoff of surface waters is a true amount of water naturally generated in the region under consideration, and consequently its variation is a true reflection of nature's fluctuation. Large value of the variable implies the risk of flooding while small value of the variable indicates the risk of drought. Therefore, it could be used to assess a city's capacity in accommodating flood waters. By China's regulation, prefectural and city governments are responsible for deriving this quantity annually for their administrative areas while the Ministry of Water Resources of China is responsible for compiling all data to obtain the quantity over the whole China. To deepen discussion, the flood fatality of the whole China was also examined in relation to the national GDP per capita adjusted for purchasing power parity (PPP).

The life loss due to flooding depends on the population exposed. A dimensionless metric term as flood mortality has been widely used in the estimation of flood disaster damage, which is defined as the number of death divided by the number of people exposed to flooding. This is a noble approach theoretically, but impractical in many situations because the estimation of the number of people exposed to flooding is flawed. It is often taken to be the registered number of residents in inundated area. However, this could be wrong in China. For example, the registered number of dwellers in Shanghai was $1368.1 \times 10^{4}$ in 2006 , but the true number of people living in Shanghai was $1815 \times 10^{4}$ in 2006 . Besides, inundation depth is not uniformly distributed within an inundated area so that a question would be "should people living in a sub-area with the inundation depth of less than $10 \mathrm{~cm}$ be excluded in calculating flood mortality? In view of the difference between the officially registered and truly resided in a city and uncertainties in methodology, this study places its attention on flood fatality instead of flood mortality.

\section{Results and Discussion}

Figure 4 shows the changes of annual flood fatality and GDP in Chongqing over the 10-year period after it became China's fourth municipality directly under the central government. Judging from the graph, the flood fatality in Chongqing has a decreasing tendency with fluctuation, while GDP has been increasing steadily. The GDP in 2009 is more than 4 times higher as compared to 1998. The average yearly income per person in Chongqing has increased from 6,433 RMB in 1998 to 26,640 RMB in 2008. Moreover, the percentage of dwellers having received university education has increased from $0.1 \%$ in 1998 to $5.7 \%$ in 2008 . Better economy means better education and we hypothesized that high education would lead to better flood risk awareness and preparedness, or even better participation in community-based flood prevention efforts.

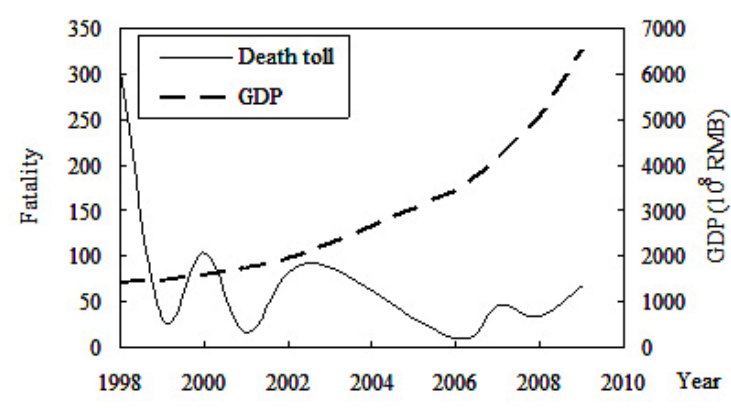

Figure 4. GDP and flood fatality in Chongqing since its economic takeoff 
Figure 5 shows that the log-transformed flood fatality is fairly well related to the annual total runoff. The correlation coefficient is 0.72 between the two and the regressed equation is:

$$
\ln (D)=0.005 F+0.99 \quad\left(\mathrm{R}^{2}=0.72, \mathrm{p}<0.05\right)
$$

or

$$
D=2.7 \exp (0.005 F)
$$

where $D=$ annual flood fatality and $F=$ annual total runoff of surface waters across Chongqing.

The exponential dependence of flood fatality on the annual total runoff is a reflection that the city was still at the mercy of nature despite of its economic jump.

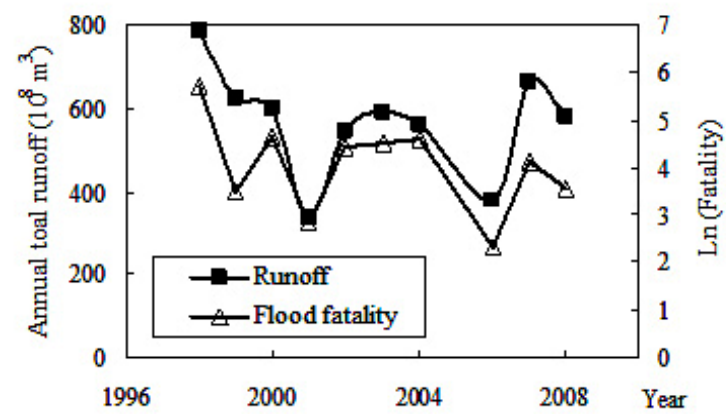

Figure 5. Relationship between flood fatality and annual total runoff of surface waters

Figure 6 shows that the number of people affected by floods over the study period fluctuated in a very similar way as the annual total runoff.

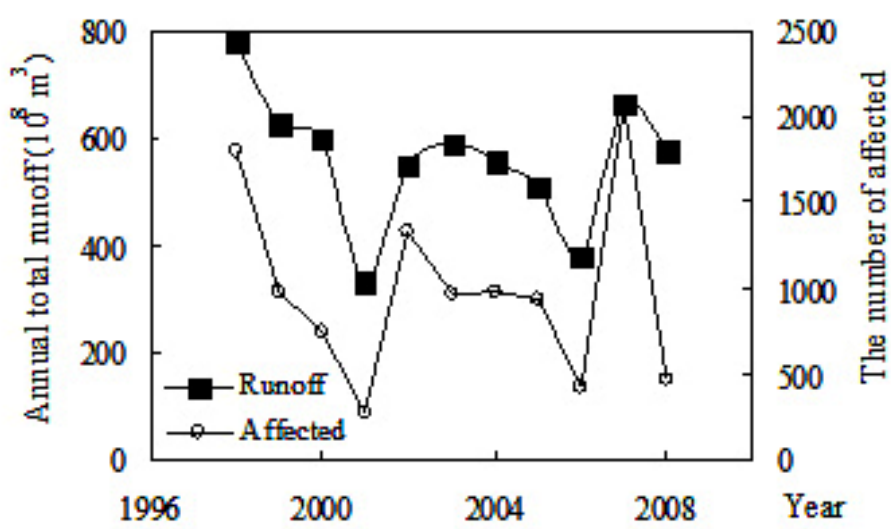

Figure 6. Relationship between the number of person affected by floods and annual total runoff of surface waters

Over the 10 years, the investment in water sector by Chongqing Municipality totaled $340 \times 10^{8} \mathrm{RMB}$. The length of levee constructed along the major rivers was $130 \mathrm{~km}$ during the 10 years and in the meantime, more than 500 dams were repaired or rebuilt, which increased the total storage by $2 \times 10^{8}\left(\mathrm{~m}^{3}\right)$. Since 2001, Chongqing has established more than 3000 geological disaster monitoring stations. The structural measures must have increased the coping capacity of Chongqing. The elevation of education and income level should have also increased the awareness of residents on water-related disasters. Besides, Jiang, Qiu, Zhang and Cheng (2009) showed that runoff at the key hydrological station of Chongqing (Cuntan station) in both flood and non-flood seasons had the descend trend during the last 50 years. In spite of the sizable investment in water-relater infrastructures and favorable hydrological conditions, the death toll and the number of people affected are still dependant to a large degree on the annual total surface water volume over the study period. This implies that the countermeasures to reduce flood disaster in Chongqing had not produced significant improvement in flood regulation during this period. It was still at nature's mercy. Therefore, it can be stated that there was at least a 10-year time lag between the city's economic 
success and true flood fatality reduction. The cause of the time lag may be attributed to medium and small-scale rivers in the region. Since Chongqing is densely covered by many medium and small rivers, and the efforts made during the study period were mainly for increasing the city's coping capacity against floods in major rivers, urban development along medium and small-scale rivers inevitably led to higher flood risk.

Urbanization in Chongqing progressed rapidly during the period of time at the rate of $20-25 \mathrm{~km}^{2} / \mathrm{yr}$. This explosive urbanization affected the small and medium-sized rivers within the city in many ways. In addition to the large increase in impervious surfaces, many natural river reaches of small and medium-sized rivers were converted to culverts. Consequently, the conveyances of these river reaches were reduced, resulting in bottlenecks for flood water passage.

On July 17, 2007, a heavy storm hit Chongqing, causing flooding in multiple areas across the city. According to the meteorological station in the Shapingba District of Chongqing, the precipitation on July 17, 2007 was $266.6 \mathrm{~mm}$, updating the highest of Chongqing ever since 1982. The hardest hit area was the Cheng Jia Qiao Town in the Shapingba District. Immediately after the disaster, China's president Hu Jintao visited this flood-battered area, expressing condolences and vowing to help the thousands affected. This reflected the degree of the disaster.

The direct cause of the disaster in the Cheng Jia Qiao Town was the overflow of the Liang Tan River, which is a tributary of the Jialing River and $88 \mathrm{~km}$ long. The overflow occurred where the natural river channel had been converted to culvert as shown in Figure 7. Flood waters overflowed there partially because of the reduction of conveyance resulting from the conversion. The maximum inundation depth in the town was $4 \mathrm{~m}$. The drainage system in the district was just designed for the 5-year storm event. As shown in Figure 8, the land-use in the Shapingba District has been greatly altered during the period of 1998-2008. The paddy fields and waterways were reduced by $50 \%$ and $17 \%$, respectively. In the same time, impervious surfaces increased by a factor of 2.4. Besides, because there was no hydraulic gauging station in the river reach through the Shapingba District, flood warning was not provided to people living near the river. It must be noted that the death toll of this flood disaster was 42 , but no life loss was directly associated to flood waters in two major rivers - Yangtze and Jialing Rivers during this weather event.

Similar flooding events happened in other years at other locations. This suggests that the rapid urbanization owing to economic growth in Chongqing has increased its exposure to flooding from small and medium-sized rivers. Wording differently, the shift of the regional flood risk source from major rivers to small and medium-sized rivers is the mechanism behind the time lag between the economic growth and flood fatality reduction.

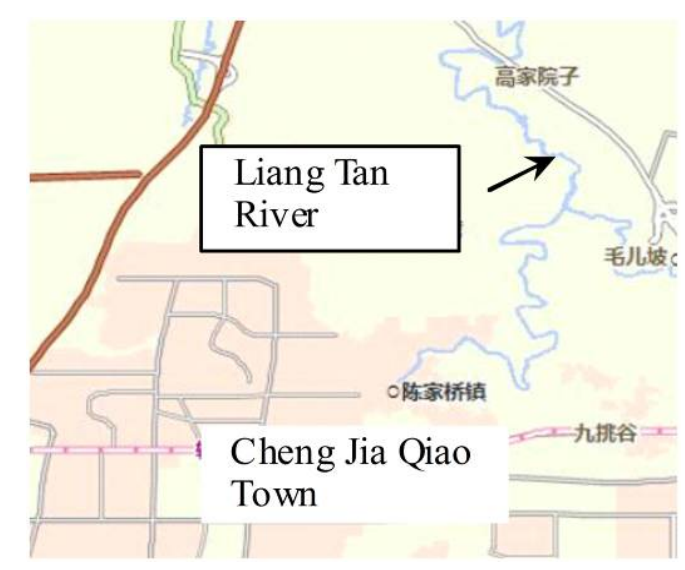

Figure 7. Liang Tan river channel converted to underground culvert at Cheng Jia Qiao Town due to economic growth 


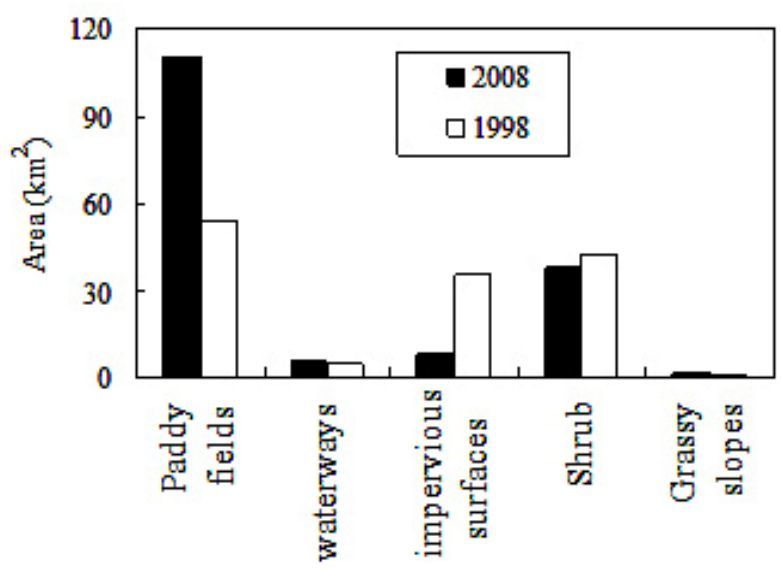

Figure 8. Land-use change in the Shapingba District

Figure 9 shows the variations of China's PPP and flood mortality from 1991 to 2007 . The flood fatality fluctuated in the 1990s but declined steadily since the end of the last century. Therefore, there was also a 10-year time lag between economic growth and flood fatality at the national level.

It is now well accepted that greenhouse gas emissions are making extreme weather events more common. Using real-world data and computer models, Ming et al. (2011) reported their finding on the link between greenhouse emissions and the observed increase in extreme rains in the Northern Hemisphere. Thus, it is likely that climate change will complex the relationship between economic growth and flood fatality reduction, and make it much more difficult to explain in an explicit way. However, an analogy could be envisaged. Urbanization increases flood risk and then economic growth reduces flood fatality with time lag. Similarly, climate change will increase flood risk, and then mitigation may bring it down with time lag.

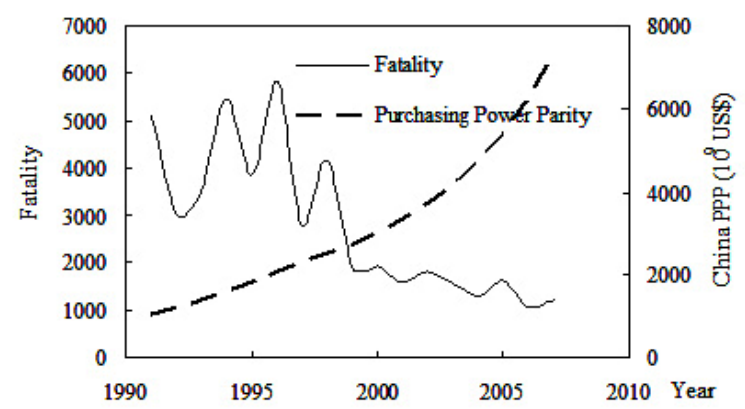

Figure 9. Annual changes of China's GDP (PPP) and flood fatality

\section{Conclusions}

By analyzing flood death toll, annual total runoff, economic and urban development of Chongqing, this study shed new light on the relationship between flood fatality and economic success. The main findings are as follows

(1) For the largest city of China and the whole china as well, the flood fatality reduction was at least 10 years lagging behind the economic growth.

(2) In the case of Chongqing, the flood fatality was an exponential function of the annual total runoff of surface waters during the 10 year period after its economic take-off.

(3) The number of person affected by floods was also found to be fairly well correlated to the annual total runoff of surface waters during the same 10 -year period.

(4) The investment in water-related infrastructures in Chongqing during the same 10-year period obviously enhanced Chongqing's capability to cope with floods in major rivers. However, along small and medium-sized 
rivers, urbanization led to the conversion of a large portion of paddy fields to impervious surfaces. Moreover, it converted some natural river channels into culverts, resulting in the reduction of river conveyance. The combination of heavy rain, increase in impervious surfaces, conversion of river channel to culvert and insufficient drainage system was found to be the cause of the severe inundation event occurred in the Shapingba District on July 17, 2007.

The lesson learned from this study was that the time lag between economic development and flood fatality reduction may be caused by irrational urban planning that resulted in poor drainage. In the long-term, economic success may bring down the flood death toll as proven by the small number of flood-caused death in developed countries. Therefore, the question for developing countries to answer will be "how to shorten the transitional period".

\section{References}

Aboelata, M., \& Bowles, D. S. (2006). Evacuation and Life-Loss Estimation Model for Natural and Dam Break Floods. Proceedings of the U.S. Society on Dam Conference.

Borden, K. A., \& Cutter, S. L. (2008). Spatial patterns of natural hazards mortality in the United States. International Journal of Health Geographics, 7, 64. http://dx.doi:10.1186/1476-072X-7-64

Boyd, E. (2005). Toward an empirical measure of disaster vulnerability: storm surges, New Orleans, and Hurricane Betsy. Poster presented at the 4th UCLA conference on public health and disasters, Los Angeles, 1-4 May.

Commission of the European Communities. (2006). Venezuela Country Strategy paper.

Dilley, M., Chen, R. S., Deichmann, U., Lerner-Lam, A. L., \& Arnold, M. (2005). Natural disaster hotspots: a global risk analysis. Disaster Risk Management Series No.5, Washington, DC: The World Bank.

Duiser, J. A. (1989). Een verkennend onderzoek naar methoden ter bepaling van inundatieschade bij doorbraak. TNO report ref. 82-0644.

Grossman, G., \& Krueger, A. (195). Economic growth and the environment. Quarterly Journal of Economics, 110, 353-377. http://dx.doi.org/10.2307/2118443

Intergovernmental Panel on Climate Change, Climate Change. (2001). Impacts, Adaptation and Vulnerability. In James McCarthy, Osvaldo Caniziani, Neil Leary, David Dokken, \& Kasey White (Eds.), Chapter 8, pp. 451-486.

Jiang, H., Qiu, L., Zhang, N., \& Cheng, X. (2009). DFA Application to Fluctuation Analysis of Runoff. Journal of Water Resources \& Water Engineering, 20(5), 154-157 (in Chinese).

Johnstone, W. M., Sakamoto, D., Assaf, H., \& Bourban, S. (2005). Architecture, modelling framework and validation of BC Hydro's virtual reality Life Safety Model. ISSH Stochastic Hydraulics 2005 conference, May 2005, Nijmegen, The Netherlands.

Jonkman, S. N., Vrijling, J. K., \& Vrouwenvelder, A. C. W. M. (2008). Methods for the estimation of loss of life due to floods: a literature review and a proposal for a new method. Nat Hazards, 46, 353-389. http://dx.doi: 10.1007/s11069-008-9227-5

Kellenberg, D. K., \& Mobarak, A. M. (2008). Does rising income increase or decrease damage risk from natural disasters? Journal of Urban Economics, 63, 788-802. http://dx.doi.org/10.1016/j.jue.2007.05.003

$\mathrm{Lu}, \mathrm{Z}$. (2000). The calculation problem about annual runoff series of return to original condition. Journal of China Hydrology, 20(6), 9-12.

McClelland, D. M., \& Bowles, D. S. (2002). Estimating life loss for dam safety risk assessment-a review and new approach, IWR report 02-R-3.

Min, S. K., Zhang, X., Zwiers, F. W., \& Hegerl, G. C. (2011). Human contribution to more-intense precipitation extremes. Nature, 470, 378-381. http://dx.doi:10.1038/nature09763

Ninno, C. D., Dorosh, P. A., Smith, L. C., \& Roy, D. K. (2001). The 1998 floods in Bangladesh: disaster impacts, household coping strategies, and response. Research Report, International Food Policy Research Institute Washington, D.C..

Peduzzi, P., Dao, H., \& Herold, C. (2002). Global Risk And Vulnerability Index Trends per Year (GRAVITY), Phase II: Development, analysis and results. UNDP/BCPR. 
Peduzzi, P., Dao, H., Herold, C., \& Mouton, F. (2009). Assessing global exposure and vulnerability towards natural hazards: the Disaster Risk Index. Nat. Hazards Earth Syst. Sci., 9, 1149-1159. http://dx.doi:10.5194/nhess-9-1149-2009

Rayhan, I., \& Grote, U. (2007). Coping with Floods: Does Rural-Urban Migration Play any Role for Survival in rural Bangladesh? Journal of Identity and Migration Studies, 1(2), 82-98.

Watson, D., Serrer, M., \& Crookshank, N. (2001). BC Hydro life safety model-a two dimensional model for estimating dam breach survival probabilities. Draft Technical Report Canadian Hydraulics Centre.

WFP (World Food Programme). (2010). Pakistan Flood Impact Assessment. 